\title{
Competencies in nursing students for organized forms of clinical moral deliberation and decision-making
}

\author{
J eanette den Uil-Westerlaken, Bart Cusveller \\ School of Health Care, Christian University of Applied Sciences, Ede, The Netherlands \\ Correspondence: Jeanette den Uil-Westerlaken. Address: School of Health Care, Christian University of Applied \\ Sciences, Ede, The Netherlands. Email: jduil@che.nl.
}

Received: October 8, 2012

Accepted: February 19, 2013

Online Published:

DOI :

URL:

\begin{abstract}
Bachelor-prepared nurses are expected to be competent in moral deliberation and decision-making (MDD) in clinical practice. It is unclear, however, how this competence develops in nursing students. This study explores the development of nursing students' competence for participating in organized forms of MDD in clinical practice, with an eye to improve nursing education.
\end{abstract}

A cross-sectional descriptive survey was conducted by a questionnaire among first and fourth year bachelor nursing students and two cohorts of novice nurses of one bachelor program in nursing. Items included the variables knowledge, attitude and skills in relation to the nurse as professional, to the nursing process, and to the organization. Data collection took place in March 2009.

Across 179 respondents, scores in MDD knowledge and skills are significantly higher for students later in nursing education, especially with regard to the variable 'nursing process'. Attitudes towards MDD score significantly higher after completing nursing training, but lower scores appeared for MDD knowledge and skills, particularly in relation to the organization.

Results suggest nursing education should reinforce students' attitudes to structural forms of MDD, and clinical practice should reinforce nurses' MDD knowledge and skills. Both education and practice should reinforce nurses’ MDD competence in relation to the organization.

\section{Key words}

Moral decision-making, Ethical rounds, Clinical ethics committees, Nursing students, Nursing education, Moral competence, Moral deliberation

\section{I ntroduction}

Across the globe, nurses face moral issues in daily patient care, including distress about communication with patients, patient privacy, end-of-life, waiting lists, and client autonomy ${ }^{[1]}$. In most countries, nurses' contribution to structural, prearranged forms of moral deliberation and decision-making (such as clinical ethics committees or ethics rounds) is valued for the sake of good patient care ${ }^{[2,3]}$. Also, the competency to engage in ethical dialogue with other professionals is supposed to help the nurse face the realities of day-to-day practice, i.e. reduce moral distress ${ }^{[4]}$. Therefore, in a country 
like The Netherlands, competencies for organized forms of moral deliberation and decision-making (or MDD) are included in the learning objectives for bachelor degree nursing education ${ }^{[5,6]}$.

Nurses' participation in organized MDD in clinical practice - i.e. meetings to address moral issues in patient care -- has not yet been studied extensively ${ }^{[7]}$, especially not how the required competencies develop in nursing students ${ }^{[8]}$. Yet acquiring MDD competencies seems to be an important part of becoming a professional nurse (Goethals et al. 2010). In order to educate nursing students with respect to MDD competencies it is vital to know how these competencies are cultivated and assessed.

\section{Background}

The notion of organized forms of MDD in clinical practice has been subject to studies both within nursing and in the wider field of health care ${ }^{[10]}$. The present article focuses neither on incidental, informal ethics discussions, nor on ethical review boards evaluating research. It highlights the importance of participation in prearranged, care-related MDD among nurses, such as ethics rounds and patient evaluation conferences, because nurses often tend to conform to the dominant institutional morality ${ }^{[11]}$. For our purposes, MDD will be used as shorthand for these structural or organized forms of clinical MDD by nurses, either within their own meetings, multi-disciplinary consultations with other professionals, or clinical ethics committees. As it is in these meetings that nurses appraise the quality of their own care and its moral aspects on a structural basis, our starting point is that nurses have to develop competencies for MDD.

The notion of competency will be understood as the unit of integrated knowledge, attitudes and skills necessary for successful performance of professional tasks ${ }^{[6,8]}$. In a previous literature review, the following eight contents of competencies for moral deliberation have been described, listed under Knowledge, Skills, and Attitudes: (1) Knowledge of moral theory and professional codes, and using them; (2) Knowledge of moral issues, recognizing and engaging them; (3) Knowledge of moral points of view, and developing them oneself; (4) Skill to consider moral perspectives of different professionals; (5) Skill to collaborate in a confident and purposeful way; (6) Open attitude with respect to sharing of and reflecting on emotions and insecurities; (7) Committed attitude to MDD; (8) Independent attitude in hierarchical relationships.

The literature reviewed suggests that the development of nursing students' competencies for organized MDD is not as effective as is desirable during undergraduate nursing education ${ }^{[1]}$. Their contribution to the quality of patient care in their clinical practice, therefore, is at stake ${ }^{[11]}$.

The purpose of this study was to explore the development of the competencies required for MDD during and after completion of bachelor degree nursing education. With the outcomes in hand, nurse educators may decide where improvement of moral formation is needed. It does so by answering the following research question: Which development in the competence for participation in MDD can be shown in nursing students comparing first year students, fourth year students and novice nurses?

\section{Method}

\subsection{Design}

A cross-sectional survey was designed to explore a population of nursing students and newly qualified nurses. From this population, respondents in different phases of their development as practitioners or students may be assessed at one single moment of data collection. A cross-sectional study was taken as an indicator of subsequent phases of development during and after nursing education ${ }^{[12]}$. 


\subsection{Respondents}

Previous quantitative studies examining nurses’ participation in MDD involved 99 and 100 participants respectively ${ }^{[13,14]}$. In order to work with comparable numbers, the entire population of first and fourth year nursing students and two year groups of alumni were recruited from the bachelor degree nursing program at a university of applied sciences in The Netherlands. This university is recognized for excellent nursing education as well as for its Christian mission statement and moral formation of nursing students ${ }^{[15]}$.

The sample consisted of three cohorts from one bachelor nursing program. Included were all full-time first-year students before their first internship, all full-time fourth-year students after all internships, and nurses five or six years after graduation who had followed the same curriculum as students. Excluded were part-time students who usually are older, more experienced clinically, and matured morally.

First and fourth-year students were asked to complete the questionnaire in class. Alumni were approached by mail, using the university's address and telephone records. Assuring anonymous and voluntary participation of respondents, written permission was obtained from the head of the school of health care and from the head of the office for external affairs of the university.

\subsection{Variables and instrument}

To identify competencies for MDD a self-assessment tool was developed, as no suitable instrument was found in the literature. Part A of this tool consisted of demographic items. Part B consisted of self-score items pertaining to MDD competencies. Part $\mathrm{C}$ consisted of open question regarding factors influencing development of MDD competencies. For reasons of brevity, this article reports the results of Part B only.

The variables of the tool were designed by combining two conceptual dimensions of competence in nursing. The first dimension contains the eight contents of MDD competence derived from our preceding literature review, distinguished as aspects of knowledge, skills and attitudes. The second dimension consists of three areas of clinical application as outlined in the Dutch professional profile of nursing practice: tasks as professional, tasks in direct patient care, and tasks in relation to the organization (or: use of self, use of nursing process, and use of institutional context). The combination of these two dimensions of eight contents of MDD competence and three areas of application yields 24 concepts. The reason for combining these two dimensions is that MDD competency development was taken to be a progression ${ }^{[16]}$, from addressing moral issues in the nursing process (patient care related) to influencing the context through MDD (organization related) in order for nurses (profession related) to arrive at the most suitable solution to an ethical issue in the unique patient situation.

As a consistency check the questionnaire included one positively and one negatively formulated item for each concept, resulting in an instrument with 48 items. For each item a 5-point Likert scale allowed for a differentiated score $(1=$ disagree completely, 2 = disagree, 3 = agree, 4 = agree completely, 5 = not applicable).

\subsection{I nstrument validity and reliability}

To establish content validity of the 48 items, Lynn's phase model was followed ${ }^{[17]}$. First, literature on the central concepts of MDD competence and organized forms of MDD was reviewed. Secondly, the 24 concepts were presented to four experts, including nurses in clinical health care, as well as an ethicist in academic research. They were asked to assess the relevance of the items in the light of the eight competency contents and the three clinical task areas. The experts confirmed the presence of the three areas of practice relating to the eight competencies in Part B and approved the questionnaire. Nursing students' self-assessment of their competence was affirmed as relevant for the research question. Quantitative assessment of the experts' evaluation was not reported. To verify face validity, thirdly, four randomly selected first and fourth-year nursing students were asked to rate the items for clarity for all participants ${ }^{[12.18]}$. A tutorial was provided and adapted on the basis of their feedback. Lastly, a pilot was conducted among twelve second-year and twelve third-year students, which resulted in minor revision of some formulations. 
After completion, students handed in the questionnaires anonymously, safeguarding against socially desired answers and inter-participant influence (Polit \& Beck, 2004). Alumni received the questionnaire by physical mail; numbering the returned questionnaires and using these numbers during data processing ensured anonymity.

\subsection{Data analysis}

Demographic data were described (Part A, not reported here), and the frequencies of scores to Part B were calculated (SPSS for Windows, version 14.0) which are reported below. Part C of the questionnaire awaits processing.

To determine internal consistency of Part B a Cronbach's alpha calculation was done. To verify the average scores of all 48 items, the 24 negative formulations were re-coded in the analysis so that they could be compared to the average scores on the 24 positive formulations.

To determine if differences between average scores are not due to coincidental factors but to a significant relation (between year group and average score) an Anova one-way variance test was done at the level $\mathrm{p}<0.05$ of significance since more than two groups were involved. Anova was also used to test the cohorts two-by-two, correcting significance for the number of comparisons done at the same time (Bonferroni comparison).

\section{Results}

\subsection{General characteristics}

Data collection was completed in March 2009. The population consisted of three cohorts of nursing students: first-year students, fourth-year students and alumni. A total of 215 students were approached with a questionnaire. A total of 179 students responded (72\%), i.e. 65 first-year students (26\%), 54 fourth-year students (22\%), and 60 alumni (24\%).

An overview of individual scores shows that percentages of individual scores are almost identical for positive and negative items. Two exceptions are items relating to independence and to a self-assured attitude; items 42 and 39, and items 43 and 40. In addition, in the extreme positions on the Likert scale positively formulated items consistently showed slightly higher scores compared to the same items with negative formulation. Regarding the moderate positions item 44 scored $19.6 \%$ for ‘disagree’ and item 53 scored $19.0 \%$ for 'agree’.

Scale reliability can also be expressed as a Cronbach's alpha value for internal consistency (see Table 1); a score between 0.70 and 0.90 indicates a high level of internal validity for part B of the questionnaire. Cronbach's alpha proved 0.94 for the eighteen items on knowledge, 0.73 for the eighteen items on attitudes, and 0.93 for the twelve items on skills. For the entire list of 48 items in Part B of the questionnaire Cronbach’s alpha was 0.95.

Table 1. Internal consistency of questionnaire items (part B)

\begin{tabular}{lllll}
\hline & Knowledge & Attitude & Skills & Part B \\
\hline N items & 18 & 18 & 12 & 48 \\
Cronbach's alpha & 0.94 & 0.73 & 0.93 & 0.95 \\
\hline
\end{tabular}

\subsection{Average scores}

Average scores of Part B of the questionnaire provide insight into the main research question: how does nurses' competence for MDD develop or, more precisely, how do three cohorts of nursing students and alumni compare when asked to score their MDD competencies? The results are shown in Table 3. 


\subsection{Knowledge}

Knowledge relevant for organized MDD in clinical practice involves moral theory and professional codes; recognizing and experiencing moral issues; and development of a moral point of view. The average scores for MDD knowledge show an identical pattern in relation to use of self as a professional, nursing process, as well as organization. First-year nursing students scored themselves as possessing modest knowledge for MDD (between 2.32 and 2.56), fourth-year students scored themselves as possessing considerably more MDD knowledge (between 2.97 and 3.23), and subsequently alumni scores on MDD knowledge were slightly higher again (between 3.10 and 3.22). Respondents rated their knowledge for MDD in relation to the nursing process consistently higher than knowledge in relation to professional tasks; knowledge in relation to tasks in the organizational context was rated lower still.

\subsection{Skills}

For items on MDD skills in relation to use of self, process and organization a similar pattern was found in the average scores, overall with slightly lower scores compared to MDD knowledge. First-year students reported not to see themselves as having MDD skills, especially in relation to their role as professionals (between 2.33 and 2.43). Fourth-year students reported themselves as having much higher MDD skills (between 2.67 and 2.87). Alumni reported themselves as having somewhat higher skills than fourth-year students (between 2.88 and 3.04).

These are the skills necessary for considering perspectives of different professionals; and for being self-assured in collaborative relationships. Here too, respondents rated their skills for MDD in relation to tasks in patient-care consistently higher than moral skills in relation to professional tasks; skills in relation to tasks in the organizational context were again rated lower still.

\subsection{Attitudes}

Where the patterns of average scores for MDD knowledge and MDD skills may be similar, even if scores for skills are lower than scores for knowledge, an altogether different pattern was visible in the average scores on aspects of MDD attitudes. These include sharing and reflecting emotions and insecurity; being motivated; and independence in hierarchical relationships.

Compared to MDD knowledge and MDD skills first year students scored their attitude to MDD relatively positive (2.79). However, the scores for attitude to MDD in relation to the nursing process were hardly higher in fourth-year students (2.84) and again hardly higher in alumni (2.91). In addition, the scores for nurses' attitudes to MDD in relation to their own professional conduct was moderate in first year students (2.50), slightly higher in fourth-year students (2.69) and only slightly higher yet in alumni (2.76).

If these average self-scores are taken as an indicator for competency development, nurses' attitude towards the use of self and the nursing process changed minimally from the beginning of their training to some time after completing their training. The exception was the result for the items on attitudes toward MDD related to the organization. Average scores in first-year students are halfway between positive and negative (2.49), but this is the only variable for which scores in fourth-years students were actually lower (2.38) than scores in first year students. Fourth-year students are inclined to report a less positive attitude towards MDD in relation to the organization; they especially reported to be more insecure, less motivated and less independent from hierarchy. However, alumni scored much higher on this aspect of MDD competencies (2.73).

In short, firstly, nursing students' self-scores on knowledge and skills for MDD were distinctly higher later in education and then marginally higher after education. Secondly, nursing students' attitudes to MDD in relation to use of self as professionals and to their patient care neither differ much from first years to fourth year or from fourth years to alumni, even if nursing students already seemed highly motivated for MDD in relation to direct patient care. Thirdly, respondents' 
attitude to MDD in relation to the organization actually scored lower later in nursing education and then higher again after graduation.

Table 2. Average scores of cohorts per concept

\begin{tabular}{lllll}
\hline & First year & Fourth year & Post-graduation & Average all \\
\hline Knowledge / professional & 2,32 & 2,97 & 3,10 & 2,78 \\
Knowledge / nursing process & 2,56 & 3,23 & 3,22 & 2,98 \\
Knowledge / organization & 2,39 & 2,92 & 3,11 & 2,80 \\
Attitude / professional & 2,50 & 2,69 & 2,76 & 2,65 \\
Attitude / nursing process & 2,79 & 2,84 & 2,91 & 2,85 \\
Attitude / organization & 2,49 & 2,38 & 2,73 & 2,54 \\
Skills / professional & 2,33 & 2,87 & 3,00 & 2,72 \\
Skills / nursing process & 2,43 & 2,87 & 3,04 & 2,77 \\
Skills / organization & 2,26 & 2,67 & 2,88 & 2,59 \\
\hline
\end{tabular}

\subsection{Testing average scores}

Although the three year groups did represent a homogeneous and normally divided population, the total size of the sample allowed for an Anova test. Results from the Anova and a Kruskal-Wallis test proved comparable. Thus post-hoc tests were done to compare differences between the groups, enabling an answer to the research question. Table 3 shows the significant differences between the three year groups, for instance regarding knowledge of moral theory and ethical codes, or recognizing and experiencing moral issues

Table 3. Significant differences between group averages per concept

\begin{tabular}{|c|c|c|c|c|c|c|}
\hline Items & Anova F & df & sig & Bonferroni comparison & sig & 95\% BHI \\
\hline \multirow[t]{2}{*}{$\begin{array}{l}\text { Knowledge related to self as a } \\
\text { professional }\end{array}$} & 64.03 & 178 & 0.00 & Fourth year First year & 0.00 & $0.4528-0.8091$ \\
\hline & & & & Alumni First year & 0.00 & $0.5821-0.9286$ \\
\hline \multirow[t]{2}{*}{ Knowledge related to nursing process } & 61.87 & 178 & 0.00 & Fourth year First year & 0.00 & $0.4883-0.8244$ \\
\hline & & & & Alumni First year & 0.00 & $0.4860-0.8127$ \\
\hline \multirow[t]{2}{*}{ Knowledge related to organization } & 54,3 & 178 & 0.00 & Fourth year First year & 0.00 & $0.3314-0.6768$ \\
\hline & & & & Alumni First year & 0.00 & $0.5320-0.8678$ \\
\hline $\begin{array}{l}\text { Attitudes related to self as a } \\
\text { professional }\end{array}$ & 13.13 & 177 & 0.00 & Alumni - First-year & 0.00 & $0.1266-0.3670$ \\
\hline Attitudes related to organization & 8.9 & 176 & 0.00 & Alumni - Fourth-year & 0.00 & $0.1453-0.5577$ \\
\hline \multirow[t]{2}{*}{ Skills related to self as a professional } & 43.15 & 176 & 0.00 & Fourth year - First year & 0.00 & $0.3513-0.7373$ \\
\hline & & & & Alumni - First-year & 0.00 & $0.4950-0.8705$ \\
\hline \multirow[t]{2}{*}{ Skills related to nursing process } & 34.44 & 176 & 0.00 & Fourth year - First year & 0.00 & $0.2510-0.6277$ \\
\hline & & & & Alumni - First-year & 0.00 & $0.4259-0.7924$ \\
\hline \multirow[t]{2}{*}{ Skills related to organization } & 32.75 & 176 & 0.00 & Fourth year - First year & 0.00 & $0.2190-0.6077$ \\
\hline & & & & Alumni - First-year & 0.00 & $0.4321-0.8103$ \\
\hline
\end{tabular}

\section{Discussion}

\subsection{Results}

By comparing three year groups of nursing students' and junior nurses' self-scores on knowledge, attitudes and skills regarding MDD, significant patterns in competency development can be postulated. During nursing education, nursing students' MDD attitudes do not develop as strongly as knowledge and skills, given these scores, especially towards 
organization-related aspects; after graduation, knowledge and skills for MDD do not develop as strongly as nurses' attitudes. Although these results have not been found in this way before, previous research has shown similar patterns ${ }^{[19]}$. This also confirms previous findings that nurses do not consider their contributions to MDD very effective ${ }^{[20]}$. Possibly, alumni have a different perception of the demands of clinical practice compared to nursing students.

Interestingly, students between the first and fourth year indicated a professional attitude in MDD, while the literature showed a different reality in clinical practice ${ }^{[21,22]}$. The results described here show a willingness to discuss personal emotions regarding ethical issues and care in first-year students ${ }^{[16,23]}$. Possibly, this motivation correlates to different entry levels in moral development; for instance, significantly high scores on empathy scales in the nursing students of this particular university may be related to its Christian background. ${ }^{[24]}$ The finding that their attitude does not improve much during education corresponds to another study showing nursing students and alumni think ethics education during their training should be more practical ${ }^{[7]}$. Nonetheless, high levels of motivation do not automatically lead to participation, assertiveness and self-confidence where organizing MDD in practice is concerned.

Although many factors may be involved, our findings suggest nursing education does not necessarily add to the improvement of nursing students' MDD attitude. Sellman suggests something along those lines on the basis of anecdotal evidence ${ }^{[8]}$. By the same token health care institutions do not seem to add much to nurses' knowledge and skills for MDD, even if nurses find MDD important. Our study does not explain why this might be so and how different educational programs yield different results. Many nurses do not find favorable conditions for the practice or initiative of MDD within health care institution, according to a literature review ${ }^{[1]}$. Research shows that practice-based ethics education helps to sustain nurses' knowledge and skills for MDD ${ }^{[19,23]}$. Even if "on the job" support in MDD is often not available, bachelor-prepared nurses themselves may be expected to stay updated with knowledge and skills required for MDD.

\subsection{Method}

From a methodological point of view, the survey described here is based on the development of an instrument with a high internal consistency. The reliability of separate items and Part B as a whole contribute to the value of the data. The positive and negative formulations show a high consistency. High response levels further reinforce this study across three substantial groups of almost equal size. Non-response bias is negligible due to a high response level. Statistical power is indicated by the one-way Anova and the significance level ${ }^{[12]}$. Whether the outcomes prove valid for the profession as a whole is yet to be ascertained by comparison to scores of nursing students and alumni from other nursing programs.

The survey focused on self-perception of competencies as well as on three different groups at the same moment in time. Strictly speaking, then, the survey took self-scores of competency as an indicator of competency and the differences between three different groups of nursing students and alumni as an indicator for development. A way to corroborate the findings would be to look at the perception of nurses' MDD competencies by others, such as nurse educators and health professionals. With an eye to education for bachelor-prepared nurses, however, interesting aspects of nurses' competencies for MDD have been found.

\section{Conclusions and recommendations}

This study indicates that nursing students do gain knowledge and skills for organized MDD during education, but that their attitude does not improve. They see the importance of MDD, especially in the direct patient care process, but education does not seem to stimulate them to be pro-active within an organizational context. It also indicates that nurses' knowledge and skills regarding MDD are at stake in clinical practice. Nurses are faced with moral conflict and distress, but do not seem to feel equipped to initiate MDD within the health care institution.

These findings are important for education, policy and nurses themselves. Our study suggests that bachelor-degree nursing education may improve ethics education by using interactive and practice oriented approaches, including casuistry, 
role-play, and simulation. It suggests to health care institutions that support is needed for nurses to make moral issues in nursing explicit in structural forms of MDD in clinical practice, for instance by continued education and in formal committees. Lastly, it suggests that nurses and the nursing profession need to take responsibility for an active role and adequate competency for MDD, especially where the relationship to the institutional context is concerned.

To strengthen nurses' competencies in organized MDD, research is required into effective ethics education, MDD, and the development of moral competencies in the nursing profession as a whole.

\section{References}

[1] Den Uil-Westerlaken J, Cusveller B. Ontwikkeling van competenties voor ethisch overleg bij hbo-verpleegkundigen (Development of competencies for moral deliberation in bachelor nursing students). Verpleegkunde. 2011; 26 : 4-12 (in Dutch).

[2] Oddi LF, Cassidy VR. Participation and perception of nurse members in the hospital ethics Committee. Western Journal of Nursing Research. 1990; 12: 307-317. http://dx.doi.org/10.1177/019394599001200304

[3] Milton LM. Institutional ethics committees: A nursing perspective. Nursing Science Quarterly. 2001; 14: 22-24. PMid:11873349 http://dx.doi.org/10.1177/08943180122108175

[4] Nathaniel AK. Moral Reckoning in Nursing. Western Journal of Nursing Research. 2006; 28: 419-438. PMid:16672631 http://dx.doi.org/10.1177/0193945905284727

[5] Leistra E, Liefhebber S, Hens H, Geomini M. Beroepsprofiel van de verpleegkundige (Profile of the professional nurse). Elsevier, Maarssen/Utrecht 1999 (in Dutch).

[6] Pool A, Pool-Tromp C, Veltman-Van Vugt F, Vogel S. Met het oog op de toekomst. Beroepscompetenties van hbo verpleegkundigen. (With an eye to the future. Professional competencies of the bachelor nurse). NIZW, Rotterdam 2001 (in Dutch).

[7] Cusveller B. Nurses serving on clinical ethics committees: a qualitative exploration of a competency profile. Nursing Ethics. 2012; 19: 431-442. PMid:22323396 http://dx.doi.org/10.1177/0969733011426817

[8] Sellman D. What Makes a Good Nurse. Why the Virtues are Important for Nurses. Jessica Kingley, London 2011.

[9] Goethals S, Gastmans C, Dierckx de Casterlé B. Nurses' ethical reasoning and behaviour: a literature review. International Journal of Nursing Studies. 2010; 47: 635-650. PMid:20096413 http://dx.doi.org/10.1016/j.ijnurstu.2009.12.010

[10] Kohlen H. Conflicts of Care: Hospital Ethics Committees in the USA and Germany. Campus, Frankfurt 2010.

[11] Dierckx de Casterlé B, Izumi S, Godfrey NS, Denhaerynck K. Nurses’ responses to ethical dilemmas in nursing practice: meta-analysis. Journal of Advanced Nursing. 2008; 63: 540-549. PMid:18808574 http://dx.doi.org/10.1111/j.1365-2648.2008.04702.x

[12] Polit DF, Beck CT. Nursing research: Principles and methods. Lippincott Williams and Wilkins, Philadelphia 2004 (7th ed.).

[13] McDaniel C. Hospital ethics committees and nurses' participation. Journal of Nursing Administration. 1998; 28 : 47-51. PMid:9745661 http://dx.doi.org/10.1097/00005110-199809000-00010

[14] Han SS, Ahn SH. An analysis and evaluation of student nurses participation in ethical decision making. Nursing Ethics. 2000; 7: 113-123. PMid:10986936

[15] Stichting Studiekeuze. Studiekeuze123 (Guide to academic programs). http://www.studiekeuze123.nl/web/site/default.aspx, accessed October 10, 2008 (in Dutch).

[16] Dierckx de Casterlé B, Meulenbergs T, Van de Vijver L, Tanghe A, Gastmans C. Ethics meetings in support of good nursing care; some practice-based thoughts. Nursing Ethics. 2002; 9: 612-22. PMid:12449998 http://dx.doi.org/10.1191/0969733002ne555oa

[17] Lynn MR. Determination and quantification of content validity. Nursing Research. 1985; 35: 382-386.

[18] Portney LG, Watkins MP. Foundations of clinical research. Applications to practice. Prentice Hall, Upper Saddle River 2000 (2nd ed.).

[19] Sporrong SK, Arnetz B, Hansson MG., Westerholm P, Hoglund AT. Developing ethical competence in health care organizations. Nursing Ethics. 2007:14: 825-837. PMid:17901191 http://dx.doi.org/10.1177/0969733007082142

[20] Miedema FA. The nurse's role on the healthcare ethics committee. HEC Forum 1993:5, 89-99. PMid:10125163 http://dx.doi.org/10.1007/BF01476543

[21] Dodd SJ, Jansson BS, Brown-Saltzman K, Shirk M, Wunch K. Expanding nurses' participation in ethics: An empirical examination of ethical activism. Nursing Ethics. 2004; 11: 15-27. PMid:14763647 http://dx.doi.org/10.1191/0969733004ne663oa

[22] Adriaansen M. Nursing education in palliative care: Content, effects and implementation. Ponsen \& Looyen, Wageningen 2007. 